\title{
La eficacia del debido proceso en las actuaciones administrativas de Tránsito y Transporte en el Dpto. del Huila (Colombia) 2006 - 2008
}

Semillero de investigación Contacto Adriana Constanza Obando, Douglas Mauricio Bautista, Amelia Cristina León, Yudy Marieth Vélez, Astrid Lorena Oyuela, Sergio Snell López, Karen Dajhanna Almario, Bibiana Paola Beltrán Liz.

Docente Tutor: Helber Mauricio Sandoval Cumbe Grupo Nuevas Visiones del Derecho

Articulo recibido: 09/09/2009 Aprobado: 16/11/2009

\section{RESUMEN}

La Ley 769 de 2003, es la encargada de la regular el debido proceso en las actuaciones administrativas de Tránsito y Transporte y donde claramente especifica en su artículo 135 el procedimiento que debería continuar cualquier persona cuando sea contraventor de las normas de transito y le sea impuesta una orden de comparendo. Por lo tanto, la relevancia de esta orden es una notificación para empezar un proceso especial donde el infractor puede ejercitar sus derechos y controvertir dichas disposiciones. Asu vez en el proceso investigativo y al aplicar los instrumentos (encuestas) estos reflejaron que no existe la aplicación de lo fijado por la Ley y lo más importante, es que los actores del proceso no desconocen el procedimientoa seguir.

\section{PALABRAS CLAVE}

Orden de comparendo, acto administrativo, infractor, audiencia, debido proceso, recursos, derecho de defensa, autoridad de transito, descargos, pruebas.

\section{ABSTRACT}

The law 769 of 2003, it is the one in charge of the regular one the due process in the administrative performances of Traffic and Transport and where clearly it specifies in their article 135 the procedure that any person should continue when she is infringer of the norms of I traffic and l/you/he/she is imposed him a comparendo order, therefore the relevance of this order is a notification to begin a special process where the offender can exercise his rights and to controvert this dispositions. In turn in the investigative process and when applying the instruments (you interview) these they reflected us that the application doesn't exist of that fixed by the Law and the most important thing, it is that the actors of the process don't ignore the procedure to continue

\section{KEYWORDS}

Comparendo order, administrative act, offender, audience, due process, resources, defense right, authority of I traffic, discharges, tests. 


\section{INTRODUCCIÓN}

Con el crecimiento acelerado de las ciudades y la necesidad de un desarrollo vial y creación del transporte masivo como alternativas de desplazamiento ágil, para la solución de problemas, riesgos y peligros generados por la actividad de transito, surge la necesidad de dar a conocer a los destinatarios del servicio de transporte, la normatividad que lo reglamenta como un carácter preventivo y no sancionatorio.

Esta problemática actual no solo reviste un carácter jurídico, sino también social derivadas de las actuaciones administrativas ante las autoridades de tránsito y transporte que tienen su origen en la imposición de un comparendo al posible infractor, en donde de manera simultanea se da inicio al procedimiento que esta determinado de manera clara en la ley y la jurisprudencia.

Ahora bien, es necesario aclarar que en los lineamientos fijados por la ley, no se dan plena aplicación en la cotidianidad, generando de esta manera una inconformidad en la sociedad en donde ven violados sus derechos como ciudadanos y como posibles infractores.

Es así que debido a lo anteriormente planteado, enfocamos esta investigación en determinar cual es la eficacia del procedimiento administrativo en cuanto a la aplicación del comparendo o sanción al posible infractor que adelantan las diferentes autoridades de transito y transportes en el departamento del Huila, mas específicamente en los municipio de Neiva, Pitalito, Garzón y la Plata, que constituyen los municipios con mas alto porcentaje poblacional, en el periodo comprendido entre los años 2006 al 2008.

\section{OBJETIVO GENERAL}

Verificar y determinar el marco de eficacia del debido proceso en las actuaciones administrativas adelantadas por las autoridades del Huila en el periodo comprendido entre los años 2006 al 2008.

\section{OBJETIVOS ESPECÍFICOS}

- Conceptualizar sobre el contenido y naturaleza jurídica de dicho procedimiento y en especial, de las órdenes de comparendo emitidas por las autoridades de TyT,

- Determinar por medio de la aplicación de los diferentes instrumentos que tan eficaz ha sido el debido proceso en las actuaciones de $\mathrm{T}$ y $\mathrm{T}$ adelantadas por estas autoridades para el periodo citado.

- Establecer si se evidencian eventos de vulneración al debido proceso en las actuaciones de $T$ y $T$ y caracterizarlos en su frecuencia y presentación

- Realizar un paralelo entre el procedimiento fijado por la ley, donde determina la actuación a seguir en el momento de la imposición del comparendo y lo que la costumbre permite realizar.

\section{MÉTODO}

Desde la vigencia del Decreto 1344 de 1970 , derogado con la Ley 769 de 2002 actual Código Nacional de Tránsito Terrestre, se observa que se ha presentado en los destinatarios de esta legislación, un gran desconocimiento de lo que implica el debido proceso en las actuaciones administrativas de Transito y Transporte

Una de las causas del problema es el desconocimiento normativo tanto de los presuntos infractores como el de las autoridades de transito acerca de la normatividad que orienta la materia, el procedimiento a seguir y demás aspectos importantes, lo que en el último caso, conduce a su indebida aplicación y violación de derechos a la 
ciudadanía y la falta de instrucción o información a la comunidad es el aspecto más notorio de las falencias en la presente investigación.

Las consecuencias son el concepto equivocado de lo que constituye la orden de comparendo, la inaplicabilidad de las funciones de las autoridades de transito y transportes, el indebido procedimiento que se siguen en las diferentes oficinas de transito y transportes y la violación de derechos entre ellos el debido proceso, contradicción, etc.

Teniendo en cuenta lo anterior, se optó como método más eficaz el descriptivo cuantitativo y cualitativo, en donde la técnica aplicada a nuestra investigación permite explorar un gran número de factores, procurando realizar el estudio a la población lo más grande posible y heterogénea, en los municipios de Neiva, Pitalito Garzón y la Plata, teniendo en cuenta que el muestreo de la población que se dirige a las diferentes oficinas de Transito fue aleatorio, permitiéndonos captar la realidad social a través de los ojos de la comunidad que está siendo estudiada, es decir la percepción que tiene de la eficacia del procedimiento administrativo que siguen las autoridades de tránsito, y este concepto de la sociedad lo obtuvimos al aplicar dos clases de encuestas a los usuarios que se acercan a la oficina de Tránsito a realizar los respectivos tramites una vez sea impuesto su comparendo facilitándonos un enfoque que nos permitirá conceptualizar frente al resultado que arroje la aplicación de los cuatro tipos de instrumentos aplicados a los individuos que se acercan a las oficinas de transito, a las autoridades de transito y un instrumento especial aplicado a los expedientes que reposan en las secretarias de transito de los diferentes municipios.

Ahora bien, una vez determinado el método de investigación, se puede continuar con el desarrollo de la investigación, para en párrafos siguientes, mostrar los resultados concretos de la aplicación de los diferentes instrumentos (encuestas), en el territorioy tiempo delimitado para la investigación.

\section{ENCUESTAS}

En cuanto a la aplicación del instrumento utilizado (encuestas) en la población de los municipios de Neiva, Pitalito, Garzón y La Plata, para el periodo comprendido entre los años 2006 - 2008, se aprecia un total significativo de 1969 encuestas, distribuidas de la siguiente manera:

Del Formulario $\mathrm{N}^{\circ} 1$ denominado "Usuarios infraccionados que acuden a la oficina de tránsito" fueron aplicados 308 instrumentos en el municipio de Neiva, 91 en el Municipio de La Plata, 84 en el Municipio de Pitalito y 76 en el Municipio de Garón, para un total de 559.

De igual forma se realizó en los diferentes municipios un total de 100 encuestas del Formulario $\mathrm{N}^{\circ} 2$ denominado "Usuarios del servicio infraccionados que acuden a la audiencia" discriminados por municipio de la siguiente manera: 59 en el Municipio de Neiva, 49 en el Municipio de Pitalito; en los municipios de Garzón y La Plata no se obtuvieron resultados en éste apartado.

El formulario $\mathrm{N}^{\circ} 3$ fue aplicado a 27 servidores públicos con cargos propios de autoridades de Transito, número que constituye la totalidad de la población que se encontraban laborando en cada municipio para el año 2007, periodo en el cual fue aplicado el instrumento en mención y distribuidas de la siguiente manera: En el municipio de Neiva existe el mayor numero de Autoridades de Tránsito con un número de catorce (14) miembros, seguido de Pitalito con seis, La Plata con cuatro y presentando un menor númeroen Garzón con tres.

De otra parte y en cuanto al formulario $\mathrm{N}^{\circ} 4$ denominado "análisis de los expedientes" que constituye en de las oficinas de tránsito contamos con un total de 1283, teniendo en cuenta que las visitas realizadas a cada municipio se lograron después de obtener permiso y de solicitar previamente fecha para la aplicación del instrumento en cada expediente, supeditados a la disposición de cada municipio en particular. 
Ya ubicados dentro del ámbito espacial, temporal, conceptual y primeramente en los resultados arrojados en cada municipio, daremos paso al análisis de los resultados o lo que se realiza de manera cotidiana en cada uno de los municipios.

\section{MARCO TEÓRICO}

La legislación del tránsito terrestre concreta la potestad sancionadora del Estado, que es consecuencia del paulatino crecimiento de las ciudades a nivel poblacional y tecnológico, así como el riesgo generado por el uso poco responsable de las vías y los medios de transporte. Así lo concibió y materializó el legislador con la (Ley 769/2002) y lo confirmó la Corte Constitucional (1994) diciendo "... no sólo potenciar la eficacia de los modos de transporte, sino garantizar su seguridad, lo cual supone una legislación rigurosa del tráfico automotor" (C-066 de 1999). Dicha normatividad delegó en la administración, la posibilidad de imponer sanciones a quienes con su actuar infringieren las prohibiciones contenidas en las normas de tránsito, previo un proceso garantista del debido proceso en el que se permitiera realizar al presunto infractor su defensa y descargos.

Al encargar a las autoridades administrativas la investigación y posterior sanción por las infracciones de tránsito, se manifiesta el poder sancionatorio del Estado, necesario para realizar sus fines y cumplir sus funciones en procura de la efectividad de los derechos de los asociados, tal y como lo ha admitido la Corte Constitucional (C-1994) al expresar que dicha potestad adquiere dos modalidades:

(...) la disciplinaria (frente a los funcionarios que violan los deberes y prohibiciones) y la correccional (por las infracciones de los particulares a las obligaciones 0 restricciones en materia de higiene, tránsito, financiera, fiscal, etc.). La naturaleza jurídica de dicha potestad es indudablemente administrativa, y naturalmente difiere de la que le asigna la ley al juez para imponer la pena, con motivo de un ilícito penal (...) (C-214 1994).
Con todo, dicha potestad sancionadora tiene límites que se configuran en las garantías sustanciales y procesales a favor del presunto infractor, orientadas a la protección de los derechos fundamentales de quien es objeto del poder correctivo de la administración, claro esta, matizado en comparación con las propias del derecho penal como paradigma del derecho sancionador y punitivo.

Por lo tanto, el debido proceso conviene tratarlo como derecho fundamental (art. 29 C.N. ), el cual es de aplicación inmediata (art. 85 C.N.). El derecho al debido proceso es el conjunto de garantías que buscan asegurar a los interesados que han acudido a la administración pública o ante los jueces, una recta y cumplida decisión sobre sus derechos. El incumplimiento de las normas legales que rigen cada proceso administrativo o judicial genera una violación y un desconocimiento del mismo." (C-339 de 1996).

El derecho al debido proceso constituye por ende, el derecho orientador del proceso administrativo, previo a la imposición de la sanción por infracciones de tránsito; cuestión que se traduce en la garantía que comprende a todas las personas de acceder a un proceso justo, diáfano y sometido a legalidad, de tal manera que la posterior sanción o privación de bienes jurídicos por parte del Estado a sus ciudadanos no sea el resultado inmediato de la vulneración al ejercicio de los derechos fundamentales de los mismos, e implica, como lo sostiene el profesor Santofimio Gamboa, (p 61) un “(..) amplio sistema de garantías que procura a través de la realidad del derecho material la obtención de la justicia como ideal estatal (...)". Es entonces la garantía consustancial e infranqueable que debe acompañar a todos aquellos actos de la administración que pretenda imponer legítima y legalmente a los sujetos cargas, castigos 0 sanciones como establecer prerrogativas, dentro de los cuales, además del debido proceso, deben operar todos aquellos principios, derechos y valores que otorguen seguridad y certeza para consolidar decisiones justas y equitativas. Las garantías propias del derecho fundamental al 
debido proceso, en las actuaciones de la administración y en particular de las autoridades de tránsito con ocasión de la emisión de un comparendo, implican un conjunto de garantías previas y posteriores al acto administrativo que da fin al procedimiento previo que permitió declarar infractor o absolver de culpa al administrado.

Como garantías previas encontramos a) el acceso libre y en igualdad de condiciones a la justicia; b) el acceso al juez natural - autoridad competente; c) la posibilidad de ejercicio del derecho de defensa (con los elementos para ser oído dentro del proceso); d) la razonabilidad de los plazos para el desarrollo de los procesos; y, e) la imparcialidad, autonomía e independencia de las autoridades.

Como garantía posterior, está la posibilidad de controvertir la validez del acto administrativo que impone la sanción, mediante los recursos de reposición y apelación de la vía gubernativa, que en materia de tránsito se interponen y sustentan inmediatamente profendala decisión, toda vez que la misma se notifica por estrados. Como extensión a dicha garantía, existe la controversia doctrinal y jurisprudencial si hay posibilidad de debatir ante la jurisdicción de lo contencioso administrativo el ajuste a derecho del acto administrativo de una autoridad de tránsito mediante la acción de nulidad y restablecimiento del derecho; quienes apoyan la posibilidad de la instancia argumentan que si bien es cierto el Decreto 01 de 1984 - Código Contencioso Administrativo - establece que la misma no juzga las decisiones proferidas en juicios de policía regulados especialmente por la ley y el procedimiento previo a la imposición de una sanción por infracciones de tránsito es de naturaleza contravencional y por ende policivo, dicho trámite es esencialmente diferente a los juicios policivos de naturaleza penal o civil, como los amparos posesorios; además, en el proceso por infracciones de tránsito no existe un juicio como tal porque:

Nos lo recuerda la Corte Constitucional (C-115/2004) (...) la actuación que adelantan las inspecciones de tránsito cuando declaran contraventor a una persona por infringir las normas de tránsito, por lo menos en cuanto se refiere a aquellas multas originadas por comparendos de tránsito cuando no hay daños ni víctimas, no constituyen en estricto sentido un juicio. No hay partes que tengan intereses opuestos, lo pretendido no es resolver un conflicto surgido entre dos o más personas y la administración no actúa como un árbitro o juez que dirime la controversia... (C.C., C - 115/2004), por lo tanto "... existe otro medio de defensa judicial al alcance de los peticionarios para obtener la protección de su derecho al debido proceso, como es acudir a la junisdicción de lo contencioso administrativo y demandar la nulidad de las resoluciones por medio de las cuales se les declaró contraventores de las normas de tránsito y se les impuso la sanción, con el consecuente restablecimiento del derecho..." (lbídem).

Ahora bien, hay quienes argumentan que no es posible acudir a la justicia contenciosa administrativa; lo sustentan en el hecho de que el trámite contravencional por infracciones de tránsito es un juicio de policía especial y por mandato literal del código contencioso administrativo están excluidos de la respectiva jurisdicción; en ese sentido la Corte Constitucional mediante la sentencia T-616 de 2006 en la que revisa un fallo de tutela contra la inspección doce Distrital de Tránsito de Bogotá y en contravía de su anterior tesis, afirmó "...los juicios de policía han sido asimilados a controversias de naturaleza jurisdiccional $y$, por ende, la providencia que se dicta dentro de ellos para poner fin a la actuación tiene idéntica naturaleza, no siendo susceptible de recursos ante la jurisdicción de lo contencioso administrativo." $\mathrm{Si}$ bien es cierto el debate doctrinal y jurisprudencial es amplio en cuanto a interpretación y hermenéutica, también lo es, que en su gran mayoría el monto de la multa por una infracción de tránsito es menor que aquello en lo que se traduce el acudir a la junisdicción; sin embargo, está sobre el tintero la posibilidad de interponer la acción de tutela cuando dentro del trámite que da lugar a proferir la sanción y se ha agotado la vía gubernativa, se han conculcado 
derechos fundamentales como el debido proceso, derecho de contradicción, que no permiten el pleno desarrollo de procedimiento por la vía ordinaria como debía suceder y no como lo es en la realidad.

Encontramos que el procedimiento administrativo con ocasión de una infracción de tránsito define: la naturaleza del comparendo, la autoridad competente, la audiencia de descargos, la notificación de la decisión y la via gubernativa.

\subsection{Teoria del procedimiento en tránsito de transportes}

En lo referente al trámite administrativo posterior a la imposición de un comparendo, cuando no es

\section{Gráfica 1}

AMBITO

ORGANISMO
Ministerio de TyT

$\begin{array}{cc} & \text { Ministerio de Ty T } \\ \text { NACIONAL } & \text { Superintendencia Ty T } \\ \text { DEPARTAMENTAL } \quad \begin{array}{c}\text { Administrativo o Secretaria } \\ \text { Departamental de Ty } T\end{array}\end{array}$

MUNICIPAL

DISTRITAL
Secretarias Municipales de Ty T

$$
\text { Departamental de T y T }
$$

\section{Autoridad designada}

Inspector de Tránsito, Inspector de Policía, Corregidor; o quien haga sus veces en cada entidad territorial Agentes de Tránsito Policía de Tránsito Urbano de la Policía Nacional - Si existe convenio con el ente territorial

\section{JURISDICCIÓN \\ Nacional \\ Control, inspección y vigilancia/ Nacional \\ Carreteras Nacionales \\ Áreas donde no haya presencia de autoridad de transito (Parágrafo 5, art 3 CNTT)}

Municipios donde no haya autoridad de transito

\section{Área urbana del municipio} $y$ corregimientos

Área urbana de los distritos especiales 
El comparendo, definido por la ley como "...Orden formal de notificación para que el presunto contraventor o implicado se presente ante la autoridad de tránsito por la comisión de una infracción",(Ley 769 de 2002 Articulo 2) no es sinónimo de multa ni de culpabilidad; como el concepto lo indica, es simplemente una orden que da inicio al trámite contravencional por infracciones de tránsito y en concordancia con el art 135 del $\mathrm{CNTT}$, el presunto infractor deberá comparecer dentro de los tres días que se entienden hábiles siguientes al organismo y autoridad de tránsito correspondiente, a solicitar fecha para celebrarse la audiencia de descargos o pagar'. Esta actuación del administrado la llamo la Corte Constitucional en Sentencia T - 616/2008 (p 17) "Audiencia de presentación del inculpado" en la cual se manifestará la anuencia o negación de los hechos que dieron lugar al requerimiento y dispondrá fecha y hora de la audiencia pública de pruebas y alegatos. Si es pagado el monto de la multa, se da fin al proceso contravencional, operando el fenómeno jurídico de asunción de las obligaciones, pero, si no acude dentro de los tres días sin causa justificada, el monto de la multa podrá ser incrementado hasta en un $100 \%$; en cuyo caso deberá presentarse dentro de los diez (10) días siguientes a la infracción desde la configuración de los hechos.

Tanto el señalamiento de los términos para comparecer, como la indicación de la autoridad competente deben estar expresamente señalados en la orden de comparendo y es deber de quien impone la infracción, comunicar verbalmente al administrado el procedimiento a seguir en virtud de la sujeción a la Constitución y la ley, por ejercer funciones públicas al servicio de la comunidad.

El comparendo puede o no ser suscrito por el inculpado; en el último evento, deberá ser signado por un testigo quien debió haber presenciado los hechos que configuraron la infracción y quien adicionalmente, ha de suministrar la dirección de su residencia para un posible requerimiento a rendir testimonio, toda vez que si quien firma el comparendo en calidad de testigo no presenció la infracción, su versión no reviste legitimidad ni legalidad alguna (CNTT, Art. 135 Inciso cuatro). Lo anterior, trae efectos sobre la notificación al inculpado del inicio de un proceso en su contra en atención a que si el comparendo no es suscrito ni por el presunto infractor ni por un testigo, aquel no se entiende notificado del inicio del proceso contravencional en su contra. (C. C. T-115/2004).

Ahora bien, en la audiencia de pruebas y alegatos el posible infractor podrá asistir con o sin apoderado (CNTT, artículo 138) y puede hacer valer todos los medios de prueba conducentes y pertinentes a establecer cualquier causal que permita absolverlo de la sanción; igualmente, es la oportunidad procesal para que el inspector de la causa decrete pruebas de oficio. Es pertinente aclarar que el comparendo no es considerado un medio de prueba en concordancia con lo expuesto por el Consejo de Estado, en la fecha del 17 de septiembre de 1997:

“...el comparendo no es un medio de prueba, por cuanto no constituye un documento idóneo para demostrar la ocurrencia de los hechos, ya que como lo dice la misma definición, es sencillamente una orden formal de citación al presunto contraventor y es en la audiencia pública realizada ante la autoridad de tránsito competente, que se decretan y se practican las pruebas que sean conducentes para determinar la verdad de los hechos..."

La decisión proferida por la administración, ya sea absolviendo o declarando infractor al inculpado (porque se es "infractor" a partir del momento que se ha demostrado la culpabilidad en el hecho y desvirtuado la presunción de inocencia conforme al principio de la buena fe), configura un verdadero acto administrativo como quiera que la voluntad de la administración crea, modifica o extingue una situación jurídica particular. La resolución es el tipo de acto administrativo adverso al inculpado, aquel

${ }^{1}$ Actualmente suscriben acuerdos de pago autorizados por el artículo 136 del Código de tránsito y transporte “...los organismos de tránsito podrán celebrar acuerdos par el recaudo de multas...". 
en el cual se le declara infractor, es susceptible de los recursos de la vía gubernativa, reposición y apelación. Estas solo proceden para sanciones que superen los 20 salarios mínimos diarios legales vigentes, o se ordena la suspensión o cancelación de la licencia para conducir que deberán interponerse y sustentarse verbalmente en la misma audiencia en la que se ha proferido la decisión.

Toda decisión adoptada en el trámite del procedimiento contravencional por infracciones de tránsito, desde la indicación de la fecha de la audiencia hasta el fallo, se notifica en estrados (CNTT, artículo 139) y deberá existir constancia de ello por parte de la administración.

En el evento en que el presunto infractor no acuda a solicitar audiencia de descargos, ni concurra dentro de los diez (10) dias siguientes, la autoridad de tránsito seguirá el proceso, entendiéndose que el presunto infractor queda vinculado al mismo, fallándose en audiencia pública y notificándose en estrados; es decir, si es declarado infractor en audiencia de fallo pierde la oportunidad de recurrir la decisión porque desde la orden de comparendo se da por notificado de los términos e inicio del proceso.

Como límite temporal al despliegue del aparato administrativo fija el CNTT en su artículo 161, un periodo de seis meses contados a partir de la ocurrencia de los hechos que dieron origen al comparendo y se interrumpe con la realización efectiva de la audiencia. Esto implica que una vez transcurridos seis meses desde la imposición del comparendo, si el funcionario encargado no ha realizado audiencia pública de fallo, lo que se traduce en que no ha proferido el acto administrativo declarándolo infractor, el administrado esta facultado para solicitar la caducidad de la acción contravencional y posterior archivo de las diligencias.

Una vez se ha proferido acto administrativo declarando infractor a un administrado y fijada la sanción y consecuente monto de la multa, si la autoridad de tránsito, quien para la ejecución de la sanción se reviste de jurisdicción coactiva, deja transcurrir tres (03) años (ley 1066 de 2006, Artículos 8,9 y 17) contados a partir de la ocurrencia del hecho sin presentar demanda tendiente a ejecutar la sanción y realizar su cobro coactivo, prescribirá la acción de cobro coactivo y se faculta para solicitar el archivo de las diligencias.

\subsection{Presentación y Análisis de los Resultados}

En este caso, la presentación y análisis de los resultados de los instrumentos aplicados a los posibles infractores, autoridades de tránsito y a los expedientes se presentarán bajo los siguientes lineamientos previstos por el artículo 136 de la Ley 769 del 2002, y la jurisprudencia en especial la sentencia T-616 de 2006 en cuanto al procedimiento fijado para el proceso contravencional por infracciones de Transito y el resultado de las encuestas aplicadas a la población escogida aleatoriamente en la esfera territorial delimitado para esta investigación y que se desarrollará de manera metodológica.

En efecto, de acuerdo a lo establecido en el art 7 de la Ley 769 del 2002, corresponde a la autoridad "(..) funciones de carácter regulatorio y sancionatorio y sus acciones deben ser orientadas a la prevención y la asistencia técnica y humana a los usuarios de las vías (...)." De lo anterior y tan solo a partir del primer paso del procedimiento, en donde las autoridades de transito son las que aplican el comparendo y que a su vez deben diligenciarlo de manera correcta, informarle al presunto infractor el procedimiento, hacerle entrega de la orden de comparendo que constituye la orden de citación o notificación, dado que así las partes aseguran la posibilidad de hacer uso de los recursos legales, el $85.2 \%$ de los casos en que la autoridad infraccionó a un usuario de tránsito, se le suministró de forma eficaz la orden de comparendo y de este porcentaje, el $92.6 \%$ es informado sobre el procedimiento a seguir, tenemos entonces, que el $14.8 \%$ no se le suministra la orden de comparendo, según fuentes tomadas de las encuestas aplicadas a las autoridades de transito. 
Por lo tanto, se le esta quebrantando el derecho de los contraventores de ser informados de las actuaciones administrativas que se siguen en su contra y así estos poder ejercer su derecho de defensa como lo sustenta la Sentencia T-099 de 1995 y de contradicción; además, el 7,4\% de la población encuestada en el F3 (corresponde al instrumento aplicado a las autoridades de tránsito ) afirma que no se le informó de la posibilidad que tienen de acercarse a las oficinas de tránsito de la jurisdicción dentro de los tres dias siguientes a la orden de comparendo, para que solicite audiencia en la cual se alegue la ilegalidad de la orden o la no comisión de la contravención.

Como quiera que este mismo interrogante fue formulado a los presuntos infractores en el momento de aplicar el instrumento F1 (Corresponde al instrumento aplicado a los Usuarios que acuden a la oficina de transito a solicitar información.), éstos indicaron en un $54.5 \%$ que la autoridad no le informo el procedimiento a seguir. Información que se confronta con lo sostenido por la Corte Constitucional en la sentencia $T-238-96$, en la indica que las notificaciones aseguran a las partes la posibilidad de hacer uso de los recursos legales, surgiendo una disparidad entre lo dicho por una y otra población objeto de investigación.

Teniendo en cuenta lo arrojado por las cifras en cuanto al suministro de la orden y la comunicación del procedimiento a seguir por parte de las autoridades de tránsito, es claro que existe un margen considerable de irregularidad en la actuación que da lugar al procedimiento administrativo especial de tránsito, lo que permite proveer, que el desarrollo de sus etapas se hace bajo la presencia de vicios que vulneran los principios de legalidad, debido proceso y publicidad, normas rectoras de todo acto de la administración. Es pertinente traer a colación el pronunciamiento de la Corte Constitucional en este sentido:

"De esta manera, en desarrollo del principio de publicidad, la notificación de las decisiones que la Administración profiere en desarrollo de un proceso y que afectan los intereses de las partes, más que pretender formalizar la comunicación del inicio, desarrollo o agotamiento de una actuación, procura asegurar la legalidad de las determinaciones adoptadas por aquélla, toda vez que al dar a conocer sus actuaciones asegura el uso efectivo de los derechos de defensa, de contradicción y de impugnación que el ordenamiento jurídico consagra para la protección de los intereses de los administrados". (Sentencia T-616-06).

Siguiendo el hilo conductor de la Ley 769 del 2002 y la sentencia T-616 del 2006, una vez sea aceptada la comisión de la infracción por parte del inculpado, este tiene dos opciones a saber: a). Pagar dentro de los tres días hábiles siguientes a la expedición del comparendo el $100 \%$ del valor de la multa. b). Cancelar el $50 \%$ del total de la multa al organismo de tránsito y el $25 \%$ a favor del Centro Integral de Atención, obligándose a asistir a un curso sobre las normas de tránsito.

Así visto el panorama, una vez emitida la orden de comparendo, el infractor, en aras de ejercer su derecho de defensa, debe tener claridad y conocimiento del procedimiento que debe seguir en las dependencias de tránsito y transporte. Esta información a su vez, la debe suministrar quien impone el comparendo, como lo mencionamos en acápites anteriores y es de gran importancia en el momento de determinar el cumplimiento de lo reglado por la Ley 734 del 2002, la que justamente en su artículo 135 menciona que ante la comisión de una infracción, la autoridad de transitó extenderá al conductor la orden de comparendo en la que ordenará al infractor, presentarse ante la autoridad de Transito competente dentro de los tres días siguientes de acuerdo a la ley 769 de 2002 artículo 135. En el mismo sentido se pronunció el Ministerio de Transporte en el Concepto MT- 1350-2-28523 del 20 de mayo del 2008, para solicitar fecha de la Audiencia de Conciliación. Pues bien, según la investigación adelantada, de la totalidad de los usuarios infraccionados que acuden a las Oficinas de Transito y Transportes, tan solo algunos de ellos 
lo hacen dentro del término legal establecido pero no tienen el conocimiento de la clase de acto al cual concurren como se desprende de observar que el $40,3 \%$ afirma que acude a una audiencia, el $32.3 \%$ que acude a descargos y el $27,4 \%$ no sabe a qué tipo de acto concurrió, son resultados que se encuentran en un estándar muy similar y no permiten diferenciar claramente si el infractor conoce el procedimiento a seguir (Resultados tomados de la fuente F2 el cual corresponde al instrumento aplicado a los usuarios que acuden a Audiencia.)

Como quiera que nos encontramos en la segunda etapa que se ha fijado por la Ley 769 del 2002, donde se presume que el presunto infractor conoce el procedimiento a seguir y que se dirige a la oficina de transito y transportes a solicitar audiencia pero tan solo es el $27,4 \%$ y un $58,6 \%$ que se acerca a la oficina a realizar el pago total del comparendo.

Concluyese de lo anterior, que se están infringiendo los derechos a ser informado por la autoridad o notificado, en este caso por medio del comparendo y por ende a ejercer su derecho defensa que está ligado indiscutiblemente con derecho al debido proceso, circunstancias que permiten analizar que no se esta dando plena aplicación por parte de las autoridades a quienes les corresponde o están en el deber de informar y de respetar los derechos de los ciudadanos.

Una vez terminada la fase anterior, donde el presunto infractor debe presentarse en los términos de ley, que corresponden a tres días siguientes a la comisión de la infracción, donde manifiesta que rechaza la imputación y la autoridad de transito, quien es la autoridad encargada, le fijara fecha y hora para la realización de la audiencia en la que se decretarán y practicarán las pruebas necesarias y se dictará el fallo correspondiente.

Ahora, dentro de los resultados obtenidos a lo largo de la investigación se determinó que una vez instalada la audiencia, quien la dirige es el funcionario de transito F2 (corresponde a fuente del instrumento aplicado a los infractores que acuden a audiencia) como lo afirma la población encuestada en los diferentes municipios. De otro lado el $97,8 \%$ afirma que actúa directamente y tan solo el 2,4\% asisten acompañado de abogado, en el desarrollo de la audiencia.

Por otra parte, de los presuntos infractores que acuden a audiencia, el 93,9\% afirmó que el secretario (a) de tránsito una vez revisadas las pruebas, escuchado al infractor y cumplidos los requisitos legales, procede a tomar una decisión, en donde se declara infractor por violación de las normas de transito en un $90,5 \%$ y solo un $9,5 \%$ fue absuelto, lo que nos deja ver que el infractor al no recibir la instrucción del procedimiento adecuado por los entes correspondientes, no conoce claramente cuáles son sus derechos y deberes en el proceso y se presenta a la audiencia sin información plena de la importancia de este procedimiento y sin percatarse que éste contiene los mismos efectos de cualquier otro proceso jurídico. Entre ellos tenemos: facultad para interponer recursos, ejercer derecho de contradicción, aportar pruebas y presentarse con apoderado...

Ahora bien, una vez concluida la audiencia, donde se debieron decretar las pruebas solicitadas por la parte si hubiere lugar a ello o decretar de oficio las que sean útiles, asi como la práctica de ellas en la misma audiencia si fuere posible de acuerdo a la Ley 769 del 2008 art. 136, una vez finalizada esta etapa, contra el auto que las decreta o las niega procede el recurso de reposición y lo decide la misma autoridad de transito; seguidamente se procede a dictar el correspondiente fallo. Sobre esta resolución procede el recurso de apelación de acuerdo a la Ley 769 del 2008 art. 142 que deberá sustentarse oralmente y en la misma audiencia.

Como quiera que el procedimiento mencionado anteriormente es el que debe seguirse en todas las secretarias de transito sin excepción alguna, el infractor en la diligencia y ejerciendo su derecho a la defensa, puede interponer los recursos necesarios sino está conforme con la respectiva decisión. En el análisis de los resultados obtenidos, el $90,1 \%$ afirma que no se le informó sobre el derecho de controvertir la medida tomada por la autoridad de 
tránsito y tan solo el $9,9 \%$ fue informado, dejando al presunto infractor sin opción, mas que acatar la decisión tomada por la autoridad que dirige la audiencia (secretario (a) de tránsito) y que en un gran porcentaje se consideran siempre infractores de la Ley, violándole así los derechos a los ciudadanos.

Por otra parte, si el contraventor no compareciere dentro del término anteriormente citado sin justa causa, las autoridades de tránsito dentro de los diez (10) dias hábiles siguientes a los precitados, tres días, debe seguir el proceso que será fallado en audiencia pública y notificado en estrados conforme lo ha expresado la Corte Constitucional en la sentencia T-616 del 2006.

Una vez concluida la audiencia, los documentos que resultaren del procedimiento de tránsito y transporte, tales como las pruebas, (fotografías, historias clínicas, documentos de identificación del infractor y del automotor etc.) acto administrativo donde se motiva el fallo y el comparendo, deben ser archivados en las diferentes oficinas de transito, como se encontró en la mayoría de los municipios que hacen parte de esta investigación.

Una vez aplicado el instrumento a los expedientes, para lograr recopilar información valiosa, se determinó que un gran porcentaje de la población, no conoce el proceso en las secretarias de tránsito y transporte. Prueba de ello es que una vez realizada la imposición del comparendo, el infraccionado tiene la posibilidad, dentro de los tres (03) dias siguientes, de presentar la solicitud para la realización de la audiencia. Ya observando el expediente, se determinó que en la mayoría de los casos el $76.5 \%$ no ha solicitado la audiencia.

Así mismo en la mayoría de los casos, es el mismo infraccionado quien no utiliza las posibilidades de ley para ejercer su derecho de defensa, ya que los expedientes analizados arrojó que en un $99,6 \%$ de los destinatarios no hace uso de los recursos. Es importante resaltar el Concepto del Ministerio de Transporte 17554 del 03 de Abril de 2008 el cual menciona la posibilidad de hacer uso de los recursos en el termino de ley, para controvertir la decisión final, perdiendo de esta manera la posibilidad de cambiar el curso del proceso. Es concordante con lo que afirman los destinatarios del comparendo cuando se les pregunta si a ellos se les informó sobre la posibilidad de ejercer recursos de ley, un $90,1 \%$ afirma no haber sido informados de tal posibilidad. Lo anterior refleja la falta de información que tienen los infractores respecto de su derecho a la defensa (Ley 769 de 2002 articulo 137 Parágrafo 1) yal debido proceso conforme al concepto del Ministerio de Trasporte número 4709 del 16 de Febrero de 2002. Con 10 anterior se puede concluir que existe una deficiencia en la manera como se le hace llegar la información al destinatario.

Ahora bien, efectivamente es el presunto infractor quien determina si aporta o no pruebas, para así ejercer su derecho de contradicción y de defensa dentro del proceso, pero al analizar los expedientes el $53.8 \%$ indicó que los infraccionados no aportaron pruebas dentro del proceso y por lo tanto no hicieron uso de los derechos que la ley le otorga, a pesar de haber solicitado audiencia.

Además se estableció que los presuntos infractores que aportaron pruebas tales como fotografias, testigos, historia o documentos clínicos en donde la más relevante fue el aporte de la copia del comparendo con un porcentaje del $89.8 \%$, al respecto el Consejo de Estado se ha pronunciado del tema en particular:

"...el comparendo no es un medio de prueba, por cuanto no constituye un documento idóneo para demostrar la ocurrencia de los hechos, ya que como lo dice la misma definición, es sencillamente una orden formal de citación al presunto contraventor y es en la audiencia pública realizada ante la autoridad de tránsito competente, que se decretan y se practican las pruebas que sean conducentes para determinar la verdad de los hechos...." (Consejo de Estado. Sala de Consulta y Servicio Civil. 17 de septiembre de 1997. Consejero Ponente: Cesar Hoyos Salazar).

Por lo tanto, no es posible catalogar el comparendo como medio de prueba, sino simplemente como 
una citación como lo menciona el Consejo de Estado.

Para finalizar nos encontramos frente a una obligación fundamental por parte de las autoridades de tránsito quienes son las que inician la relación directa con el infraccionado y consiste en la necesidad de que el comparendo sea diligenciado con los requisitos que la misma ley impone, sin dejar escapar ningún detalle para que no exista la posibilidad de una nulidad futura del comparendo como lo expresa el Concepto del Ministerio de Transporte 59673 del 15 de diciembre de 2005. Ministerio de Transporte.

\section{CONCIUSIONES}

Apartir de la vigencia de la Ley 769 de 2002 se inició una nueva etapa para el trámite contravencional por infracciones de tránsito, el cual se caracteriza por la regulación del procedimiento que debe llevar a cabo el organismo competente. Es evidente que no había una historia escrita sobre este procedimiento, luego las secretarias de tránsito y transporte están presentando una constante evolución que va a la par del desarrollo de las líneas institucionales del Ministerio de Tránsito y Transporte, la Corte Constitucional y el Consejo de Estado.

Las autoridades de tránsito que imponen comparendos reciben capacitación sobre el procedimiento para la imposición de sanciones por infracciones a las normas de tránsito, luego las órdenes de comparendo cumplen todos los requisitos de forma que los validan para iniciar el trámite. De otra parte, aunque las autoridades de tránsito manifiestan que informan sobre los derechos y garantías que tienen los inculpados, estos expresaron que la autoridad de tránsito de manera general no les proporcionó información y en las ocasiones que lo realizó fue insuficiente para poder hacer uso de los derechos a los que había lugar.

Las autoridades de tránsito y transportes poseen el conocimiento para la imposición del comparendo, pero no para instruir al usuario frente al procedimiento con él para que ejerza los derechos con los que cuenta y no se vulnere el derecho fundamental al debido proceso.

Los presuntos infractores acuden a los organismos de tránsito a solicitar audiencia, cuando no reconocen que han cometido la infracción, sin embargo desconocen los derechos de defensa que pueden ejercer en la audiencia de descargos. Es así que no solicitan pruebas, no exigen que se presente la autoridad de tránsito que les impuso el comparendo, actúan de manera pasiva en el desarrollo de la misma. Igualmente desconocen los recursos que pueden ejercer (el de reposición y de apelación), por ende no saben en qué momento procesal pueden hacer uso de ellos, ni ante qué autoridad ejercerlos.

Lo cierto es que a lo largo de la investigación adelantada se reflejó una evidente disparidad entre la realidad y la normatividad vigente, debido a que la información obtenida de los instrumentos aplicados a los usuarios no cumple con el debido proceso de las autoridades administrativas referentes a los comparendos emitidos por las autoridades de Tránsito en los municipios de Neiva, Pitalito, Garzón y La Plata. 


\section{BIBLIOGRAFÍA}

- Barroilhet Acevedo, Claudio y Diaz Díaz, Alejandro. (2002). Derecho del Transporte, Volumen 1. Madrid, Libromar, Editorial, Ltda.

- Brito Ruiz, Fernando. (2005). El debido proceso en las actuaciones administrativas. En: Temas de Derecho administrativo contemporáneo. Bogotá, Centro Editorial Universidad del Rosario.

- García de Enterría, Eduardo y Fernández, Tomás Ramón. (2000). Curso de Derecho Administrativo. Madrid: Civitas, 2 Tomos.

- Gozaini, Osvaldo Alfredo. (2004). El debido proceso: derecho procesal constitucional. Buenos Aires,

Rubinzal-Culzonieditores.

- Hoyos, Arturo. (1996). El debido proceso. Bogotá, Temis.

- Molano López, Mario. (1995). Transformación de la función administrativa. Bogotá, Pontificia Universidad Javeriana.

-Sánchez Torres, Carlos Ariel. (2004). Teoría General del Acto Administrativo. Bogota D.C. Legis.

- Santofimio Gamboa, J. O. (2003). Tratado de Derecho Administrativo, Acto Administrativo. Tomo II. Bogotá, Universidad Externado de Colombia.

\section{CONCEPTOS}

- Concepto Ministerio de Tránsito y Transporte MT-1350-2-28523 del 20 de mayo del 2008.

- Concepto Ministerio de Tránsito y Transporte MT-17554 del 03 de Abril de 2008.

- Concepto Ministerio de Tránsito y Transporte MT-4709 del 16 de Febrero de 2002.

- Concepto Ministerio de Tránsito y Transporte MT-4709 del 16 de Febrero de 2002.

\section{NORMATIVIDAD}

- Constitución Política de 1991, publicada en la Gaceta Constitucional No. 116 de 20 de julio de 1991 Disponible en: http://www.secretariasenado.gov.co/senado/basedoc/arbol/1001.html

- Decreto 1 de 1984 (enero 2), Diario Oficial No. 36.439, del 10 de enero de 1984, Código Contencioso Administrativo.

- Ley No 769 de 2002, agosto de 06, por la cual se expide el Código Nacional de Tránsito Terrestre y se dictan otras disposiciones. Disponibleen

http://www.secretariasenado.gov.co/senado/basedoc/ley/2002/ley_769a_2002.html

- Ley No 1066 de 2006, julio 29, por la cual se dictan normas para la normalización de la cartera pública y se dictan otras disposiciones.

\section{JURISPRUDENCIA}

Corte Constitucional

Corte Constitucional, sentencia C-530 del tres de Julio de 2003. M.P.: Dr. Eduardo Montealegre Lynett.

Corte Constitucional, sentencia C-066 del 10 de Febrero de 1999, M.P.: Fabio Morón Díaz

Corte Constitucional, sentencia T-572 del 26 de octubre de 1992, M.P.: Jaime Sanín Greiffenstein.

Corte Constitucional, Sentencia C-214 del 28 de abril de 1994, M.P.Antonio Barrera Carbonell.

Corte Constitucional, sentencia T-115 de 12 de Febrero de 2004. M.P.: Jaime Córdoba Triviño.

Corte Constitucional, Sentencia T-616 de tres de agosto de 2006. M.P.:Dr Jaime Araujo Rentería.

Corte Constitucional, sentencia T-238 de 30 de Mayo de 1996. M.P. Dr. Vladimiro Naranjo Mesa.

Corte Constitucional, Sentencia T-099 de 03 de Marzo de 1995, M.P. Dr. José Gregorio Hernández Galindo.

\section{Consejo de Estado}

- Consejo de Estado. Sala de Consulta y Servicio Civil. 17 de septiembre de 1997. Consejero Ponente:

Cesar Hoyos Salazar

- Concepto Ministerio de Tránsito y Transporte 59673 del 15 de diciembre de 2005.

- Concepto Ministerio de Tránsito y Transporte, MT-1350-2-59791 del 15 de diciembre 2005.

- Consejo de Estado, Sala de lo Contencioso Administrativo, Sección Tercera. Consejero Ponente:

Dr. Jesús Maria Carrillo Ballesteros, Sentencia: Septiembre 13 de 2001, Referencia: Expediente 12487.

- Consejo de Estado. Sala de Consulta y Servicio Civil. 17 de septiembre de 1997. Consejero Ponente:

Cesar Hoyos Salazar. 